\title{
Valencias de la dialéctica negativa. Totalidad antagónica y posibilidad de emancipación sin totalidad
}

\section{(Valences of the Dialectic. Antagonistic Totality and a Possibility of Emancipation without Totality)}

\author{
Facundo Nahuel MARTíN
}

Recibido: 14 de mayo de 2014

Aceptado: 9 de julio de 2015

\section{Resumen}

Continuadores posteriores de la teoría crítica de la sociedad han cuestionado a Adorno por caer en una lógica de la emancipación frustrada aparentemente contradictoria, que reflexiona sobre la dominación social en condiciones bajo las cuales, empero, se declaran cerradas las posibilidades de transformación histórica. Sin embargo, sostengo que su teoría social remite también a un concepto novedoso de la emancipación sin totalidad, relevante para la reconstrucción de la teoría crítica ante los cuestionamientos pluralistas lanzados hacia el concepto de "totalidad".

Palabras clave: Adorno, pesimismo, teoría crítica, emancipación.

\begin{abstract}
Later developers of critical theory have criticized Adorno for allegedly blocking any possibility of social change, thus falling in a pessimistic and contradictory logic of frustrated emancipation under which there is no apparent alternative to social domination. I will attempt to show that this criticism is partially correct. Nevertheless, I also suggest that his social theory offers an original concept of
\end{abstract}


emancipation without totality, providing relevant keys for the contemporary pursue of critical social theory under a partially pluralistic context.

Keywords: Adorno, pessimism, critical theory, emancipation.

\section{Introducción}

En la continuación posterior de la teoría crítica de la sociedad, la acusación más común dirigida a Adorno es probablemente la de caer en un pesimismo sin salida. Autores como Habermas o Wellmer han cuestionado que el pensamiento de Adorno caería en un impasse pesimista, que minaría la consistencia del propio proyecto crítico. Esta clase de objeciones, al mismo tiempo, han sido contestadas por una serie de intérpetes, desde los años noventa hasta la actualidad, como Schweppenhäuser, Zamora, Maiso o Cabot. Estos lectores objetan que el cambio de perspectiva operado por Habermas tiende a desconocer o abandonar el campo de problemática adorniana, antes que ofrecer una superación teórica inmanente.

En este trabajo, centrándome en Dialéctica negativa, intentaré revisitar el citado problema del "pesimismo" adorniano, pero bajo la perspectiva de la filosofía de la historia. Esto conducirá a una discusión con la interpretación de Habermas y Wellmer, pero también recurriré a algunos conceptos importantes de Moishe Postone. Sostendré que hay, efectivamente, una deshistorización de la dominación social en Dialéctica negativa, que conduce al problema del pesimismo. Empero, al mismo tiempo, la idea de una dialéctica negativa ofrece también la posibilidad de repensar el concepto de emancipación en la tradición de la teoría crítica, delineando la posibilidad de una "emancipación sin identidad".

Adorno tematiza el fracaso de la totalidad para erigirse como sistema cerrado, completo y exento de contradicción. El fracaso de la totalidad se correlaciona con la insuprimible no-identidad entre sujeto y objeto, universal y particular, hombre y naturaleza. La articulación de la persistente no-identidad como algo no eliminable remite a la vez a una lógica de la emancipación frustrada y a una posibilidad de emancipación sin totalidad. Trataré de mostrar, pues, que el "pesimismo" adorniano no es resultado de la tesis de la no-identidad o imposibilidad de realizar la totalidad, sino de una deshistorización ilegítima del concepto de totalidad antagónica.

En las primeras dos secciones del texto evaluaré la adecuación y el alcance de la objeción de pesimismo. Intentaré también discutir las vías mediante las cuales una reconstrucción contemporánea del pensamiento de Adorno podría sortear esa objeción. Sostendré que la deriva pesimista atribuida a Adorno puede enmarcarse en la construcción de una filosofía pesimista de la historia universal de la que parece no haber salida. Su pensamiento cae, por momentos, en una protesta por la eman- 
cipación frustrada, en un intento (de difícil consistencia) por sostener la crítica de la sociedad, una vez que no se reconocen alternativas viables a la dominación vigente. Siguiendo especialmente las contribuciones de Postone, sostendré que la noción de totalidad antagónica no puede revestirse legítimamente de alcance histórico-universal, sino que debe circunscribirse de manera estricta al plano de la especificidad histórica del capitalismo. Esto significa que la teoría crítica de la sociedad, frente al putativo pesimismo indiscriminado de Adorno, puede continuarse mediante un giro a la especificidad histórica que sitúe el concepto de totalidad antagónica de modo preciso en la dinámica de la sociedad moderna y ya no en una protohistoria de la modernidad que remite, al fin, a orígenes arcaicos. De ese modo sería posible romper con la lógica de la emancipación frustrada y recuperar algunos de los trazos más fecundos del pensamiento adorniano.

En la segunda parte del trabajo sugeriré que, allende las dificultades en torno a la especificidad histórica, Adorno provee también las bases para un nuevo concepto de la emancipación social, liberado de las promesas totalizantes de algunas concepciones marxistas heredadas. Sostendré que la no-identidad entre universal y particular, que bloquea la realización final de una totalidad bajo un sujeto-objeto idéntico, no tiene relación con la caída en el pesimismo y el abandono de toda intencionalidad emancipatoria. Si la deshistorización de la "totalidad antagónica" pone en cuestión la consistencia del proyecto adorniano de la teoría crítica, en cambio la tesis de la no-identidad convierte a Adorno en un filósofo particularmente sugerente para pensar la continuación contemporánea de la teoría crítica de la sociedad. La caída en el pesimismo debe atribuirse a la deshistorización del concepto de totalidad; mientras que, en cambio, la tesis de la no-identidad permite repensar importantes nociones heredadas en la tradición marxiana.

\section{Estado de la cuestión}

La acusación de pesimismo constituye, sin duda, una de las más importantes objeciones que Adorno ha recibido de parte de los continuadores posteriores de la teoría crítica. El más importante de estos críticos es probablemente Habermas, para quien "la Dialéctica de la ilustración apenas deja ya en pie perspectiva alguna desde la que poder escapar del mito de la racionalidad con arreglo a fines" (Habermas 1989: p. 143). Según Habermas, Adorno y Horkheimer socavan el potencial liberador de la modernidad al identificar sin salida racionalidad, mito y domino. Esto, a la vez, pondría en cuestión la consistencia de su proyecto crítico:

La sospecha de ideología se torna total, pero sin mudar de dirección. Se vuelve no solamente contra la funcionalización irracional de los ideales burgueses, sino también contra el potencial de razón de la propia cultura burguesa, afectando así a los fundamentos 
de una crítica ideológica que pretendiera poder proceder en términos inmanentes; empero sigue en pie la intención de conseguir un efecto de desenmascaramiento (Habermas 1989: p. 149).

Albrecht Wellmer, en una investigación de impronta habermasiana, ha señalado una problemática similar. Si la ilustración, con su carga de opresión sobre la naturaleza y las personas, se identifica con la historia universal, entonces la teoría crítica de la sociedad no parece dirigirse a metas realizables. La apuesta adorniana a una reconciliación entre sujeto y naturaleza se fuga a un reino imposible más allá de la historia. La teoría crítica se vuelve entonces melancolía ilimitada, salvaguarda estética de una aspiración emancipadora que no se puede ejecutar en el mundo social:

La crítica de la razón instrumental se ve necesitada de una filosofía histórica de la reconciliación, de una perspectiva utópica, porque de otro modo ya no sería concebible como crítica. Pero si la historia se ha de trocar en lo otro de la historia para poder salir del sistema de enmascaramiento de la razón instrumental, entonces la crítica del presente histórico se convierte en una crítica del ser histórico (Wellmer 1993: p. 80).

Un importante grupo de pensadores ha contestado estas críticas, en lo que podemos caracterizar como una recuperación de Adorno contra Habermas. En el ámbito español, planteos como los de Maiso (2010), Cabot (1993) o Zamora (1999) señalan que el pensamiento de Habermas no guarda continuidad con la primera generación de la teoría crítica de la sociedad, sino que posee un proyecto fundamentalmente distinto que simplemente abandona los problemas adornianos hacia una reflexión independiente, que muchas veces constituye un retroceso en términos de potencial crítico y grado de conciencia sobre la catástrofe de la ilustración en el siglo XX. Maiso habla, así, de la "invención de la tradición” donde Habermas pretende erigirse en "corrector" de la teórica iniciada por Adorno y Horkheimer (Maiso 2010: p. 135). Esta invención de una continuidad teórica, sin embargo, oculta la profundidad de la cesura introducida por Habermas, cuyo pensamiento "trae consigo una transformación total del significado, de los objetivos y del alcance de esta «tradición teórica»" (Maiso 2010: p. 136).

Cabot, a su turno, sostiene que el "cambio de paradigma" formulado por Habermas no implica una superación inmanente del pensamiento de Adorno, sino un simple abandono de la problemática original. "No cabe, pues, hablar en ningún momento de «superación» sino de «deslizamiento» o «alejamiento» del núcleo de problemas planteados por Adorno" (Cabot 1993, p. 11). Habermas sometería la filosofía Adorniana de la reconciliación al molde formalista de un restrictivo concepto de la racionalidad, que no alcanza a penetrar en los argumentos de Adorno y simplemente, deslizándose hacia un nuevo paradigma, los juzga exteriormente a partir de una serie de supuestos independientes. 
Estas críticas guardan relación con los planteos de Schweppenhäuser en su Ethik nach Auschwitz, quien sostiene que la reformulación habermasiana es en verdad un retroceso crítico. Habermas, con su formalismo racionalista, quedaría por detrás de Adorno como testigo del siglo, aferrándose aun a un concepto ingenuamente afirmativo de la modernidad y la ilustración. Esta "superación teórica", así, no podría dar cuenta precisamente del contenido experiencial del pensamiento de Adorno, motivado por el desmoronamiento de la ilustración como tal, ante la extrema violencia a la que condujo la historia toda de occidente. Habermas, así, incurre en la "idealización del principio moral universalista", la "hipostatización de una normatividad lingüística reducida de modo cientificista", "la exclusión de la cuestión del bien moral" y la "renuncia a una concepción sustantiva de la justicia" (Schweppenhäuser 1993: p. 230, traducción propia). La "superación" habermasiana del "pesimismo" de Adorno, pues, sería simplemente un abandono de los pilares de su planteo crítico, hacia una formalización cientificista del concepto de razón que es en definitiva incapaz de lidiar con la catástrofe histórica, moral y filosófica de Awuschwitz.

José Zamora (2004) da cuenta de los motivos históricos que llevan al devenir "negativo" de la crítica social. Adorno escruta críticamente la idea de progreso, cuya aceptación y prosecución afirmativas llevaron a la debacle del siglo XX. Frente a los emergentes del antisemitismo, la cultura de masas y el debilitamiento del individuo por los mecanismos de asimilación del mundo administrado, se torna preciso indagar en una "protohistoria de la modernidad" que desate (al menos en forma teórica) el nudo que ata desde el origen progreso, ilustración y dominio:

Pero si ya antes de la catástrofe europea de la segunda guerra mundial y del genocidio judío Adorno y los otros intelectuales de la Teoría Crítica habían centrado su reflexión en las complicidades de la civilización moderna con la barbarie, la quiebra que éstos acontecimientos representaban terminó de rasgar definitivamente el velo de optimismo que ocultaba las contradicciones del proceso emancipador moderno (Zamora 2004).

Para estos autores, la objeción de "pesimismo" esgrimida por Habermas deforma el contenido experiencial del pensamiento de Adorno, presentando como una dificultad psicológica del autor, lo que es propiamente impuesto por las condiciones históricas. El pensamiento de Adorno sería, entonces, un esfuerzo por captar el desastre del siglo dando cuenta de "la ruptura epocal que señala Auschwitz, que no dejaría nada intacto" (Maiso, 2010: 50). Adorno intentaría pensar la estructura catastrófica de la historia de la civilización, comprendiendo que las condiciones que llevaron a la barbarie extrema estarían aun latentes en la sociedad moderna. Su filosofía negativa no constituiría, pues, un simple pesimismo, que pudiera ser "superado" al modo de un error teórico, sino que respondería a las condiciones históricas. Habermas, en su recuperación de un concepto afirmativo de la ilustración, caería 
por detrás de Adorno, ignorando simplemente la cesura civilizatoria que acaeció en Auschwitz y reponiendo un concepto formal de racionalidad incapaz de lidiar con el desmoronamiento del proyecto ilustrado en el siglo XX.

Con este debate como trasfondo, intentaré revisitar la discusión sobre el "pesimismo" de Adorno, volviendo sobre el terreno específico de la filosofía de la historia. Para ello, apelaré de manera central al concepto de totalidad social desarrollado por Moishe Postone en Tiempo, trabajo y dominación social. Intentaré mostrar que Adorno efectivamente cae en un impasse "pesimista", pero con un argumento diferente al de Habermas. Los planteos de Maiso, Cabot, Zamora o Schweppenhäuser son importantes, en la medida en que sitúan la discusión en términos adecuados al pensamiento del propio Adorno y su experiencia histórica. Sin embargo, no dan cuenta de una dificultad de consistencia en su intento por esclarecer históricamente la experiencia del siglo XX. Adorno intenta elucidar las condiciones que llevaron a la barbarie civilizatoria. Esta elucidación cobra sentido bajo el trasfondo normativo de la exigencia de que la barbarie no se repita. Sin embargo, Adorno también eterniza subrepticiamente las condiciones para la barbarie, absolutizando aquello que pretende criticar. Esta absolutlización se da, sostendré, en el específico plano de la filosofía de la historia: en lugar de situar de manera precisa la dominación social (que encierra las condiciones de posibilidad de la barbarie moderna) en las determinadas condiciones del capitalismo y sus estructuras fetichistas, Adorno acaba por atribuir los procesos contradictorios de la dominación a una protohistoria de la modernidad de bases imprecisas, identificadas con un proceso arcaico de orígenes antediluvianos. La dominación, así, se deshistoriza, pues no es atribuida a condiciones superables, sino a una catástrofe de duración histórico-universal de la que no hay salida. Esclareceré este punto apelando a las formulaciones de Moishe Postone, quien sienta las bases para precisar el alcance histórico de la totalidad antagónica.

Postone ha formulado una aguda crítica acerca de los presupuestos históricos y epistemológicos de la primera generación de la teoría crítica. Intenta mostrar que estos pensadores permanecen ligados a las hipótesis del "marxismo tradicional". Ante el despliegue de la "sociedad administrada" y el "capitalismo de Estado", Adorno y Horkheimer se habrían quedado sin elementos para continuar la crítica inmanente del capitalismo. La caída en el pesimismo social y político, entonces, se debería a la confusión entre una forma histórica particular del capitalismo (el capitalismo liberal del siglo XIX) y el capitalismo en general. Incapacitados para comprender la nueva situación, creyeron enfrentarse a "una modalidad en la que se han superado las contradicciones del capitalismo" (Postone 2006: p. 172), que barrería las bases históricas de la crítica de la sociedad.

Frente al cierre de la crítica históricamente situada bajo el capitalismo de Estado, Horkheimer se habría volcado a la interioridad del pensamiento para pre- 
servar una formulación crítica que perdió autorreflexividad social, adoptando la tesis adorniana de la "no-identidad de sujeto y objeto". "Horkheimer no sólo sitúa la emancipación fuera de la historia, sino que, para salvar esta posibilidad, se siente ahora impelido a introducir una ruptura entre sujeto y objeto" (Postone 2006: p. 173). Si bien no se ocupa en detalle de Adorno, Postone parece hacerle extensiva su evaluación del pensamiento de Horkheimer. En las pocas menciones explícitas que le dedica, en efecto, habla de "la idea de Adorno de la totalidad como necesariamente afirmativa" (Postone 2006: p. 130), de "unidad no contradictoria que conduce a la universalización de la dominación" (Postone 2006: p. 205). Adorno, para Postone, consideraría la dominación social capitalista como fundamentalmente nocontradictoria, como una totalidad cerrada y solvente. Sostendré que se equivoca en este punto: para Adorno la totalidad de la dominación es sistemática e inherentemente contradictoria, desgarrada por antagonismos insuperables.

Sin embargo, Postone también enfatiza el problema de la especificidad histórica de la dominación social, ofreciendo una crítica que posee puntos de contacto con la Habermas, aunque en términos diferentes. Focalizándome en este punto, intentaré volver sobre el problema del "pesimismo", en términos de una discusión de filosofía de la historia.

En consecuencia, [Adorno y Horkheimer] ya no fundamentaron la reificación en una forma históricamente específica y transformable (la mercancía), sino que la enraizaron transhistóricamente en la confrontación, mediada por el trabajo, de la humanidad con la naturaleza. Habermas señala que con este giro la Teoría Crítica no pudo articular los estándares de su crítica (Postone 2006: p. 271-272, cursivas agregadas).

Postone sitúa las categorías de la dominación social en términos históricamente determinados, a partir de un análisis del capital como sujeto del proceso histórico reificado en la modernidad. En este trabajo sostendré que se equivoca al atribuir a Adorno una visión de la totalidad social como cerrada y carente de contradicciones. Sin embargo, al situar la categoría de dominación social (ligada a la constitución de una totalidad social contradictoria) en términos históricamente específicos, este autor permite tanto identificar las razones de la deshistorización de la dominación en el pensamiento de Adorno, como proveer las bases para la reformulación del proyecto crítico en términos de superior consistencia teórica.

No se trata de que Adorno considere a la totalidad del capitalismo tardío como carente de contradicciones o cerrada, como sostiene Postone. Tampoco, como plantea Habermas, de que la falta de una distinción entre razón instrumental y razón comunicativa. Intentaré mostrar, en cambio, que las dificultades de consistencia en la teoría de Adorno se deben a que acaba por deshistorizar la dominación social, situándola en procesos de alcance demasiado imprecisos y difíciles de determinar. Un giro a la especificidad histórica en la categoría de dominación, informado por la 
relectura que Postone hace de Marx y la teoría crítica, permitiría sortear estas dificultades.

\section{Las condiciones mínimas para una teoría crítica de la sociedad}

Para clarificar el debate, voy a establecer tres condiciones mínimas para la formulación solvente de la teoría crítica de la sociedad. Apropiándome de manera algo laxa del canónico texto de Horkheimer, "Teoría tradicional y teoría crítica" (Horkheimer 2003), pretendo sintetizar estas condiciones mínimas del siguiente modo:

1 La teoría crítica ofrece, verbigracia, una crítica de la dominación social en el capitalismo. No es una teoría descriptiva que busque establecer una serie de enunciados meramente contrastables sobre lo existente, sino que tiene a la vez un contenido descriptivo y normativo. La teoría crítica confronta lo existente con una serie de posibilidades liberadoras que se encierran en su seno, pero que la sociedad actual no puede realizar sin subvertirse a sí misma. Los enunciados normativos no se fundamentan de manera pura sino en el interior de una trama histórica dada. Sólo que esos mismos enunciados normativos apuntan más allá de lo históricamente dado, poniendo de relieve el carácter contradictorio de las circunstancias sociales vigentes. Se trata de una teoría de la distancia entre las posibilidades liberadoras y las condiciones opresivas inherentes en la sociedad establecida.

2 La teoría crítica debe considerar que la estructura de la dominación social es contradictoria. Esto significa dos cosas. (2a) La totalidad social capitalista no puede sistematizarse de manera armoniosa y coherente sobre sus propios principios: se regenera a sí misma produciendo y reproduciendo contradicciones estructurales que la desgarran paso a paso. La totalidad establecida reproduce constantemente su carácter antagónico. (2b) La totalidad vigente genera constantemente posibilidades emancipadoras que ella misma no puede realizar. La teoría crítica es conciencia de las contradicciones estructurales de la sociedad como apertura a una trascendencia histórica que parte de la lógica de las relaciones ya constituidas pero las puede superar. Esto significa que la teoría crítica medita sobre la dialéctica de la modernidad, dialéctica entre las posibilidades liberadoras generadas en la modernidad capitalista y las estructuras reificadas que obturan tales posibilidades.

3 La teoría crítica se asienta sobre los principios de especificidad y autorreflexividad históricas. Si la sociedad capitalista encierra algunas posibilidades emancipatorias que no puede realizar, eso significa que la lógica de la dominación 
social que la sustenta no puede ser transhistórica sino que se asienta en estructuras históricamente determinadas susceptibles de ser superadas mediante una transformación social. La teoría crítica es autorreflexiva en cuanto destaca la especificidad (y por ende eventual caducidad) histórica de la lógica de la dominación social en el capitalismo.

Estas tres condiciones no pretenden establecer una "concepción formal" de la teoría crítica. Tal cosa sería contradictoria: no hay teoría crítica "en general", sino teoría crítica de la sociedad capitalista moderna, atada a sus bases históricamente determinadas. La teoría crítica es la conciencia históricamente autorreflexiva de la contradicción entre las posibilidades liberadoras y las persistencias opresivas inherentes a la modernidad capitalista. No es legítimo, por lo tanto, establecer condiciones formales para la teoría crítica en general. Se trata de un pensamiento ligado al contenido, que busca reflexionar sobre sus condiciones históricas y por lo tanto no puede formalizarse en términos puros. El propósito de esta somera síntesis es, en cambio, destacar los límites más allá de los cuales la teoría crítica no puede formularse de modo solvente. Primero, una teoría crítica de la sociedad no centrada en el concepto de dominación perdería todo filo emancipador, pues se resolvería ya en un conjunto de enunciados descriptivos moralmente asépticos (teoría tradicional), ya en una ética o una metafísica ahistóricas (filosofía tradicional). Segundo, una teoría crítica que negara el carácter contradictorio de la dominación social (por ejemplo, declarando que la totalidad existente se "cerró" sobre sí misma) sería inconsistente. La autorreflexividad histórica de la teoría crítica exige que ésta no imposte un marco normativo desde afuera a la realidad social: las contradicciones que la teoría patentiza son inmanentes a su objeto. Si el objeto de la teoría (la moderna sociedad capitalista) no fuera contradictorio (en tanto su dinámica inmanente genera desgarramientos estructurales pero también anuncia posibilidades que la trascienden), entonces la propia teoría crítica no podría siquiera ser enunciada y la única conciencia posible de la realidad social recaería en la teoría tradicional o la ideología. Tercero, una teoría crítica sin bases históricas precisas acabaría por socavar su propia intencionalidad emancipatoria. La crítica de la dominación social tiene sentido únicamente bajo el supuesto de que esa dominación, algún día, deje de imperar. Luego, la crítica social debe circunscribir históricamente, de modo lo más preciso posible, el alcance de la dominación social. A la luz del estado de la cuestión ¿Cumple Adorno con estas condiciones mínimas de solvencia? Examinaré esto punto por punto.

1) En primer lugar, es evidente el pensamiento adorniano es una formidable crítica de la dominación social. El concepto de totalidad antagónica posee singular importancia para clarificar la crítica de la dominación de Adorno. Está crítica está 
centrada en el aplastamiento de lo no-idéntico por la totalidad. El "Excurso sobre Hegel" de Dialéctica negativa es importante porque en él se analiza la lógica de la dominación, comprendida como aplastamiento de lo no-idéntico por la identidad, desde el punto de vista de la filosofía social e histórica. El énfasis no está puesto, entonces, en la relación entre sujeto y naturaleza, sino en la mediación de universal y particular. Adorno se apropia irónicamente de las categorías de la filosofía de la historia hegeliana para pensar la dominación como un proceso objetivo, que conforma a los sujetos pero los precede y que remite a la forma como las personas se vinculan entre sí e manera sistemática en la sociedad. Apela al concepto hegeliano de "espíritu universal" [Weltgeist] para interpretar la dominación social (reducción de la diferencia a la identidad, construcción de una totalidad contradictoria) en el plano de las relaciones entre universal y particular. El espíritu universal es la sociedad misma, en tanto asume una forma fetichista o posee una dinámica automática e independiente de los particulares. Sólo bajo condiciones fetichistas, la sociedad compone una totalidad antagónica. "Totalidad" no significa simplemente el conjunto, el todo o la suma de los particulares, sino que remite a la forma de su articulación. La sociedad posee forma y dinámica de totalidad contradictoria únicamente en la medida en que su despliegue global se encuentra autonomizado frente a los particulares, girando sobre su propia dinámica, cuyos mecanismos fetichistas prescinden de los sujetos y se les imponen como una necesidad ajena.

El Weltgeist no realiza la libertad en la tierra, sino que motoriza la dinámica de la dominación, encerrada en la lógica ciega y autonomizada del vínculo social reificado. Constituye la historia misma en cuanto se levanta frente y contra los individuos. "El espíritu del mundo se convierte en algo autónomo con respecto a las acciones individuales (...) y con respecto a los sujetos vivos que realizan esas acciones" (Adorno 2008: p. 280). Las relaciones entre los particulares son regidas por leyes extrañas que ellas no pueden modificar bajo las condiciones dadas. Se trata de un mundo social autonomizado con respecto a los sujetos vivientes, un mundo que se rige por una legalidad independiente para la que ellos son contingentes. El espíritu es la sociedad mistificada que se enfrenta a las personas como un poder independiente. El pensamiento de Adorno, pues, no coincide con una filosofía pura, pero tampoco con la teoría social tradicional, sino que se centra en el escrutinio crítico de las formas heterónomas de la sociedad vigente. La totalidad de la dominación tiene, a la vez, un carácter intrínsecamente contradictorio, por lo que conforma una totalidad contradictoria.

2) Ahora bien, ies (2a) autocontradictorio el despliegue totalizante del Weltgeist? ¿Logra la dominación social del espíritu universal "cerrarse" sobre sí misma hasta componer un sistema sin fisuras? En este punto es preciso hacer justicia a Adorno que, contra los lugares comunes de su recepción posterior (como en 
los pasajes de Postone citados en el "Estado de la cuestión"), en ningún caso cae en la inconsistencia de declarar "cerrada" la dominación social. Por el contrario, el Weltgeist patentiza la unidad de totalidad y contradicción: se trata de una totalidad antagónica. El espíritu del mundo no construye un universal genuino, sino que perpetúa sus antagonismos estructurales. Es la unidad de totalidad y antagonismo, que reúne a los individuos imponiéndose sobre y contra ellos: "por encima de las cabezas, los atraviesa y en tal medida es de antemano antagónico" (Adorno 2008: p. 280). El espíritu como totalidad social necesita de los particulares, pues sólo se realiza a través de sus acciones. Al regirse por una legalidad propia, sin embargo, niega a esos mismos individuos, sometiéndolos a una existencia superimpuesta, cuyas leyes ellos no pueden controlar. El espíritu como sujeto de la totalidad social genera un mecanismo heterónomo para los sujetos.

La totalidad social fetichista, autonomizada frente a los particulares y vuelta ciegamente sobre sí misma, acaba por reducir toda diferencia a la identidad, trocando la totalidad en contradicción. Lo universal no tolera a lo particular, que debe sin embargo subsumir. Por eso mismo no es genuinamente universal, sino contradictorio, antagónico y particular: "lo que no aguanta nada particular se delata por ello a sí mismo como algo que domina particularmente" (Adorno 2008: p. 292). La universalidad del espíritu universal, que lo dota de unidad y continuidad, es sin embargo antagónica y socava toda unidad. La totalidad niega la diferencia, no la acomuna: "no es meramente unidad dentro de la multiplicidad, sino que, en cuanto postura ante la realidad, es estampada, es unidad sobre algo" (Adorno 2008: p. 292). La totalidad es, según su propio principio, algo polarizado y carente de totalidad. Niega a los particulares en el acto de reunirlos, oponiéndoseles como unidad abstracta y exterior, regida por leyes indiferentes hacia ellos. Así, la totalidad se vuelve negativa, contradictoria y particular. El principio de su totalismo, la autarquía frente a todo lo particular y diferente, es el mismo de su falta de unidad, que la vuelve totalidad de la contradicción, totalidad antagónica.

Adorno y Horkheimer dedicaron buena parte de sus estudios sobre la industria cultural y el antisemitismo a clarificar el "debilitamiento" de los factores subjetivos de la resistencia a la dominación social. Su teoría analiza lúcidamente los mecanismos de integración de las masas oprimidas en la dominación social. Recurriendo a una conjunción original de marxismo y psicoanálisis, ${ }^{1}$ analizaron cómo la "sociedad administrada" coloniza crecientemente las subjetividades, reduciendo los márgenes de la resistencia al dominio. Sin embargo, una comprensión global del pensamiento de Adorno nos muestra que no puede haber ninguna totalidad completamente cerrada. La dinámica de la totalidad social es antagónica en virtud de su estructura fundamental, estructura que perdura más allá del pasaje del liberalismo

\footnotetext{
1 Para un trabajo detallado sobre el recurso al psicoanálisis para la explicación del fascismo y la industria cultural, véas el importante trabajo de Maiso Blasco 2010: pp 337-414.
} 
decimonónico a la sociedad administrada del siglo XX. No se puede hablar de "totalidad cerrada" en el pensamiento de Adorno: si la dominación cosificada logra integrar psíquicamente a los individuos, ello no suprime en modo alguno la contradicción objetiva entre universal y particular, que es inherente a la totalidad antagónica por su lógica y estructura. Que los márgenes de los particulares para resistir la dominación se reduzcan en un contexto determinado conlleva, podemos decir, un "suavizamiento" integrador de las contradicciones sociales, pero en ningún caso su supresión. Por lo tanto, Postone no comprende a Adorno cuando le achaca abandonar el análisis del carácter autocontradictorio de la dominación social.

Por lo demás (2b) ¿produce la dominación social una serie de posibilidades liberadoras que ella misma no puede realizar? ¿Se anuncian, en la tupida malla del Weltgeist, los cimientos de un proyecto de modernidad liberador? ¿Hay en el pensamiento de Adorno una comprensión de la dialéctica de la sociedad moderna que contraste las posibilidades liberadoras y las persistencias opresivas del iluminismo vigente? Al comienzo de Dialéctica del iluminismo se dice: "la crítica a la que (...) se somete al iluminismo tiene por objeto preparar un concepto positivo de éste, que lo libere de su petrificación [Verstrickung, "enredo", "traba"] en ciego dominio" (Adorno y Horkheimer 2002: p. 11). La posibilidad de un concepto positivo del iluminismo remite a la liberación de un potencial encerrado en la totalidad de la dominación social, potencial que ésta produce pero no puede realizar sin transformaciones profundas. Es preciso encontrar en la dominación del Weltgeist aplastante las bases para un proyecto de ilustración posible, que rompa su asociación con la dominación.

La posibilidad de "desenmarañar" el nudo entre iluminismo y dominación remite a la idea de progreso. Adorno rompe con la asociación entre teleología histórica y progreso: no hay progreso en la historia de la totalidad social, sino sólo más allá de ella. El progreso está ligado al movimiento opresivo del Weltgeist pero encierra la posibilidad de trascenderlo. La dominación social, en suma, parece generar efectivamente potencialidades liberadoras que, empero, la trascienden. El de progreso es un concepto antinómico porque está condicionado por la totalidad histórica, pero su ocasión genuina apuntaría más allá de ella. La idea de progreso encierra la posibilidad de una "constitución social íntegra" (Adorno 1993: p. 28) en una humanidad que ya no conformaría una totalidad antagónica sino un universal reconciliado:

El modo más sencillo de explicar esto es definir la humanidad como lo que no excluye absolutamente nada. Si fuese una totalidad que no contuviese en sí misma ningún principio limitador, sería una totalidad libre de la coacción que somete a todos sus miembros a tal principio, y ya no constituiría ninguna totalidad, ninguna unidad forzada (Adorno 1993: p. 29). 
El progreso se hace posible en el filo entre los ideales emancipadores y la reproducción de la totalidad opresiva. El concepto de progreso remite a las posibilidades liberadoras que romperían con la totalidad antagónica, generando una universalidad genuina, reconciliada con lo particular, ya no regida por una legalidad independiente y abstracta. Pero esas posibilidades emergen históricamente sólo sobre la base de la lógica de la dominación social y su eventual ruptura. "Si la humanidad sigue atrapada por la totalidad que ella misma configura, entonces no ha existido, al decir de Kafka, ningún progreso; pero al mismo tiempo, sólo una totalidad permite pensarlo" (Adorno 1993: p. 29, cursivas agregadas). El Weltgeist como totalidad de la dominación sienta las bases del concepto emancipatorio del progreso, cuya concreción a la vez impide. Si "cuanta mayor identidad impone el espíritu dominador, tanta mayor injusticia padece lo no idéntico" (Adorno 1993: p. 33), al mismo tiempo la idea de progreso remite a la posibilidad de un universal que ya no sea opresivo, que ya no se desgrane en la dinámica de una totalidad antagónica.

Como señala Max Pensky, Adorno promulga, frente a la totalidad de la contradicción, una recuperación de lo transitorio, lo particular y finito, buscando desarrollar "una teoría crítica sensible ante lo transitorio en la historia" (Pensky 2004: p. 1, traducción propia). La sensibilidad hacia lo particular se correlaciona con la denuncia de la totalidad espiritual como opresiva y antagónica, como una totalidad desgarrada. La posibilidad del progreso, pues apunta a la posibilidad liberadora de "otra" universalidad, ya no gobernada por principios heterónomos contrapuestos a los particulares, sino dedicada a la felicidad de los individuos.

¿De qué manera, bajo qué dinámica social, la totalidad de la contradicción gesta la posibilidad de una universalidad liberada? Podemos colegir que la contradicción entre universal y particular, en la que cae el Weltgeist, atestigua la discrepancia entre sus propias aspiraciones de universalidad y su realización efectiva como garante de una opresión particularista. El Weltgeist se pretende universal, total, omniabarcador. Sin embargo, al regirse por principios de desarrollo autónomos, independientes de los particulares, autonomizados sobre sí mismos, se contrapone a los sujetos vivos. Así, podemos decir, el Weltgeist genera una "normatividad" (incluir lo particular en lo universal) que él mismo defrauda. Al caer en una contradicción insalvable con lo particular, la dominación de la totalidad antagónica se revela falsa con respecto a sus propios parámetros, pues se ve desahuciada como totalidad y por ende particularizada. Por lo tanto, la apuesta emancipatoria por un universal reconciliado, ya no regido por una legalidad fetichizada, no surge de un ideario a priori sino de pretensiones normativas fundadas en el Weltgeist dominante, cuya realización exige empero trascenderlo. El carácter antagónico, desgarrado de la totalidad, que no logra reconciliar la relación entre lo universal y lo particular, apunta a un estado de cosas superador. 
3) Finalmente, ¿es históricamente determinado el desarrollo del Weltgeist? En este punto es preciso reconocer, al menos parcialmente, el peso de críticas como las de Habermas o Postone, válidas al menos en cuanto señalan la deshistorización de las condiciones de la dominación social en la teoría de Adorno. El problema del "pesimismo" puede entonces comprenderse bajo una luz diferente. Ya no se trata del "cierre" de la totalidad de la dominación, sino de que Adorno es extremadamente vago al determinar las condiciones históricas en que ésta se gesta. El Weltgeist, como trasfondo objetivo de la lógica de la dominación, parece tener un valor histórico doble. Por un lado, remite a dominación social en el capitalismo, bajo las condiciones únicas e irrepetibles de la modernidad burguesa. Por otro lado, parece imprimirse sobre una historia universal negativa de origen antediluviano.

Basta una breve colección de citas para sugerir que Adorno es, por lo menos, ambiguo a la hora de precisar el alcance histórico de la totalidad antagónica y oscila entre situarla históricamente e hipostatizarla como destino inexorable, insertándolo en una filosofía de la historia universal pesimista. Por un lado, Adorno emplea conceptos cuyo campo de aplicación está acotado a la determinación histórica del capitalismo: "la ley marxista del valor" (Adorno 2008: p. 276), "el desarrollo de la producción capitalista" (Adorno 2008: p. 281), "el fetichismo del proceso de producción en la sociedad de canje" (Adorno 2008: p. 283). A la vez alterna estas afirmaciones con otras que parecen apuntar a tesis transhistóricas o a la construcción de una historia universal: "construcción filosófica de la historia" (Adorno 2008: p. 279), "durante milenios la ley del movimiento de la sociedad ha hecho abstracción de los sujetos individuales" (Adorno 2008: p. 281), "no hay ninguna historia universal que lleve desde el salvaje hasta la humanidad, sí, sin duda, una que lleva de la honda a la megabomba" (Adorno 2008: p. 295). Adorno pasa -a veces abruptamente- de consideraciones definidamente históricas sobre el capitalismo moderno a reflexiones de carácter sumamente vago sobre la historia universal. Esto habilita a críticos como Schnädelbach a atribuirle una "filosofía de la historia sin historia" [Geschichtsphilosophie ohne Geschichte] (Schnädelbach 2004: p. 151) en la que se descuida toda historización concreta del objeto de estudio, al inscribirlo en una filosofía pesimista impostada de antemano.

El concepto de Weltgeist posee para Adorno un grado de especificidad histórica demasiado vago. Esto legitima la crítica de pesimismo: si la dominación social, al final, no se asienta en condiciones históricas precisas, sino que es arrastrada a partir de un proceso histórico-universal, resulta casi imposible imaginar vías concretas para su superación efectiva. Esto significa que, al final, las posibilidades liberadoras generadas por el Weltgeist, que podrían movilizar la historia más allá de la totalidad antagónica, no tienen perspectivas de concreción real. Si la dominación es un mal histórico-universal, que la humanidad arrastra desde tiempos arcaicos, entonces las posibilidades liberadoras presuntamente generadas por la historia opresiva 
de la civilización son irrealizables. La falta de atención a la especificidad histórica (condición para la superabilidad eventual) de la dominación social, cierra el paso a toda posibilidad transformadora.

Ante esta "equivocidad histórica" de Adorno, podemos decir que existe una totalidad social antagónica, vertebrada por un sujeto global como el Weltgeist, únicamente en la medida en que las relaciones sociales se gobiernan a sí mismas de forma fetichista, obturando las posibilidades de autodeterminación de los particulares. Esta situación se cumple únicamente bajo el primado del valor como forma social en el capitalismo. Sólo bajo el signo histórico del capital, el complejo funcional de los individuos relacionados, que se realiza a través de los particulares, se constituye sin embargo como algo externo a ellos mismos. Entonces las relaciones sociales regidas por el valor abstracto se vuelven opacas e inapelables para los individuos, autonomizándose frente a ellos. Asumen, pues, una complexión global que se rige a sí misma. El valor estructura una forma de dominación social basada en un principio abstracto que se superpone a toda violencia personal. Esa forma de dominación mutila las capacidades de autodeterminación de los sujetos, sometiéndolos a su propio imperio abstracto. Adorno reconoce por momentos este corte histórico, especialmente en sus estudios sociológicos:

El dominio de los hombres sobre los hombres se realiza a través de la reducción de los seres humanos a agentes y pacientes del intercambio de mercancías. La estructura total de la sociedad tiene la forma concreta por la cual todos han de someterse a la ley del intercambio (Adorno 2004: p. 273).

La "dominación mediante el intercambio" transfigura las formas directas de dominio personal en formas impersonales de aplastamiento de los hombres por la factura abstracta de sus relaciones sociales. Esta totalidad impone a todos los individuos, con independencia de su posición de clase, una dinámica social automática y reificada que prescinde de ellos. Sin embargo, el principio de dominación mediante el intercambio no es situado históricamente de manera precisa. Por momentos, parece levantarse sobre condiciones específicas del capitalismo, mientras que en otros momentos se erige en lógica del conjunto de la historia hasta el presente. Para clarificar este problema, recurriré nuevamente al a bibliografía secundaria.

\section{Giro a la especificidad histórica}

Existen algunos trabajos que analizan especialmente la relación entre el pensamiento de Adorno y las categorías de la crítica del capital. Recientemente, Dirk Braunstein (2011) ha mostrado detalladamente que Adorno se ocupó de la crítica de la economía política, reconstruyendo su evolución intelectual desde ese punto de 
vista. "Las obras filosóficas, sociológicas y de historia del arte de Adorno, y esto es igualmente cierto para sus escritos teóricos musicales y literarios y sus ensayos sobre el psicoanálisis, deben ser comprendidos como modelos de una crítica de la economía política desarrollada como teoría social" (Braunstein 2011: p. 394, traducción propia). La lectura de Braunstein se centra en la absorción de las contradicciones sociales bajo los mecanismos del mundo administrado. "La práctica revolucionaria, que habría requerido la abolición de la sociedad comprendida como mala, Adorno la considera como pospuesta indefinidamente; la totalidad de la economía la vuelve inmediatamente imposible" (Braunstein 2011: p. 396). Braunstein, en este punto, reconstruye cómo la totalidad de la dominación ha asimilado sus propios antagonismos al punto de que no es posible esperar su superación inmediata, pero sin dejar de ser contradictoria, lo que permite la formulación de una teoría crítica, aun en condiciones de un indefinido aplazo de la praxis. Esta lectura, entiendo, es correcta desde el punto de vista del punto 2 a (carácter contradictorio de la totalidad antagónica). Sin embargo, omite revisar cuidadosamente el problema de la especificidad histórica de la dominación. Un análisis centrado en este punto (la filosofía de la historia) podría mostrar que Adorno es al menos ambiguo a la hora de situar las categorías de la dominación social en condiciones históricas superables.

Puede decirse algo similar sobre el libro Dialektik der Wertform de Hans Georg Backhaus (1997). Backhaus destaca el aporte de Adorno para la interpretación de la teoría marxiana del fetichismo. Especialmente en su seminario de verano de 1962, Adorno se ocupó del fetichismo de la mercancía, mostrando que las relaciones sociales en el capitalismo son gobernadas por una suerte de "abstracción real" u objetiva. Las relaciones entre las personas, entonces, no existen de modo directo como relaciones sociales, sino que asumen la forma mistificada de relaciones cuasiobjetivas, gobernadas por una suerte de abstracción que no parte del pensamiento de los sujetos, sino de la factura objetiva de las relaciones sociales mismas. La lectura de Backhaus muestra, pues, la importancia de Adorno para comprender el significado del valor y el fetichismo de la mercancía, pero no analiza la manera como la teoría del fetichismo se inserta en una filosofía de la historia de duración mucho mayor. Backhaus, podemos decir, hace uso de las categorías adornianas para su propia lectura de Marx, antes que preguntarse si Adorno precisa o no la especificidad histórica de la categoría de dominación.

La interpretación de Jan Weyand (2001) refuerza mi propia posición al respecto. Para Weyand, la teoría de Habermas es "consistente pero acrítica", mientras que la de Adorno es por su parte crítica pero inconsistente (Weyand 2001: p. 13, traducción propia). "Si la dialéctica de la ilustración se basa en la unidad del sacrificio y el fraude y la negación de la naturaleza (...) que está en el corazón de la racionalidad civilizatoria, no hay manera posible de salir de esta dialéctica" (Weyand 2001: p. 27). La teoría social crítica no puede identificarse con una denuncia de la civili- 
zación como tal, so pena de poner en entredicho su propia solvencia crítica. Weyand, frente a este problema, intenta reconstruir la teoría del sujeto de Adorno reconduciéndola al plano de las relaciones sociales. Muestra, entonces, que la crítica de la dominación puede fundamentarse a partir del contexto del intercambio [Tauschzusammenhang] y el capital total [Gesamtkapital].

Chris O'Kane (2013), por último, analiza en detalle la teoría del fetichismo de Adorno, en buena medida en continuidad con el pensamiento de Backhaus. Diferenciando de modo preciso entre fetichismo y reificación, O'Kane destaca la importancia de Adorno para formular una crítica contemporánea de la dominación social. Sin embargo, también considera que Adorno es "impreciso" la hora de proveer una teoría crítica del fetichismo, "y por lo tanto, antes que una crítica de una sociedad particular, corre el riesgo de ser simplemente una crítica de la sociedad como tal" (O’Kane 2013, p. 160, traducción propia).

El problema de la especificidad histórica de la dominación puede clarificarse, finalmente, contrastando el pensamiento de Adorno con las investigaciones de Postone. Según este autor, las relaciones sociales capitalistas componen una totalidad porque se fundan en el principio autonomizado, automediador, del valor. Postone reinterpreta la relación entre Marx y Hegel a partir de la noción de totalidad: "la crítica madura de Marx no supone una inversión «materialista» y antropológica de la dialéctica idealista de Hegel, al estilo de la emprendida por Lukács. Al contrario, es, en cierto sentido, la «justificación» materialista de dicha dialéctica" (Postone 2006: p. 94). Las relaciones sociales capitalistas están gobernadas por el principio autonomizado del valor. El capital, valor que pone valor, subordina la producción para el uso a la producción para el cambio como fin en sí mismo. El principio mediador de la totalidad, el valor, se funda a sí mismo y gobierna todos los momentos de lo social. "Para Hegel, el Geist constituye una totalidad general (...) [que es] resultado de su propio desarrollo" (Postone 2006: p. 132, en cursivas y en alemán en el original). El valor, principio automediador de lo social, es totalista porque se gobierna a sí mismo y conduce globalmente a la sociedad según sus leyes autonomizadas, independientes de la voluntad de los sujetos. La dialéctica idealista de Hegel tiene un "núcleo racional" en tanto refleja la operatoria históricamente específica del valor, que se reproduce a sí mismo (el capital es valor que pone valor) a espaldas de los sujetos (para reforzar este punto véase Arthur 2004: pp 1-17).

No es casual que Postone recurra al mismo concepto que Adorno, el Geist hegeliano: en ambos casos se trata de un principio estructurante de lo social que prescinde de los particulares y se autogobierna en forma fetichizada. Pero Postone clarifica que el Geist emerge únicamente sobre la base de la dinámica históricamente específica del capitalismo, con la automediación alienada del valor. Las relaciones capitalistas mediadas por el trabajo conforman una totalidad históricamente específica. Podemos, por lo tanto, prescindir de una comprensión totalista de la historia 
universal, pero no así de la sociedad capitalista. Las sociedades no capitalistas, según Postone, también presentan formas de dominación, que incluso pueden ser brutales y violentas. Pero se trata de situaciones de dominación personal o directa: dominación sustentada en la violencia inmediata ejercida por un grupo social, que posee los medios de la fuerza, sobre otros. En el capitalismo, en cambio, la dominación social se funda en las estructuras impersonales de la sociabilidad reificada. El capital organiza una peculiar lógica de dominación por la totalidad social, regida por sus principios independientes de desarrollo, en un contexto de igualdad formal entre los individuos. La dialéctica de lo universal y lo particular bajo el Weltgeist, que encierra a la vez el fracaso de la totalidad antagónica para cerrarse sobre sí misma y la promesa de un futuro universal reconciliado, es una dialéctica especificamente moderna: se basa en las peculiaridades asumidas por el vínculo social en el capitalismo. Así, partiendo de la reconsideración de Postone, es posible situar con mayor precisión la lógica de la dominación social.

El antagonismo entre universal y particular bajo la forma de totalidad antagónica (y la promesa de su superación) pertenecen a la dialéctica de la sociedad capitalista, no a una dialéctica protohistórica de origen arcaico. Adorno, sin embargo, sitúa la dominación en el capitalismo como un jalón más en lo que acaba siendo una filosofía de la historia pesimista, bajo la cual la dominación vendría repitiéndose desde el origen de la cultura como tal. Postone, pues, se equivoca al endilgar a Adorno una concepción "cerrada" de la totalidad de la dominación, pero al mismo tiempo provee las bases conceptuales para situar el problema del pesimismo en el plano de la filosofía de la historia.

En resumen, de las tres condiciones mínimas que propuse para la formulación consistente de la teoría crítica de la sociedad, parece que Adorno no cumple con la tercera condición (atención a la especificidad histórica). Nos ofrece una brillante reflexión sobre el fracaso de la totalidad antagónica para sistematizar su propio dominio, aun en las condiciones de integración social del mundo administrado. Sin embargo, al mismo tiempo parece anular por principio la posibilidad de transformación social en virtud de una deshistorización o generalización arbitraria de las formas de dominación en el capitalismo. Su planteo ofrecería entonces una dialéctica de la emancipación frustrada, insistiendo en la conciencia crítica de la dominación social, allí donde no parece haber posibilidades reales de cambio. Este bloqueo de las posibilidades de cambio no se funda, a la vez, en la integración de las contradicciones sociales por la totalidad de la sociedad administrada. Suficiente bibliografía prueba que la integración de las contradicciones no llega al punto de anularlas o suprimirlas, de modo que el aplazo de la praxis enarbolado por Adorno no acarrea una inconsistencia de la crítica (analicé esto en el punto 2a de las "condiciones mínimas de solvencia"). La relectura que propongo, en cambio, hace énfasis en el punto 3: hay efectivamente una absolutización de la dominación social en el pensa- 
miento de Adorno, pero ésta no se funda en los mecanismos de integración de la sociedad administrada o el capitalismo tardío. Por el contrario, la hipóstasis de la dominación se debe a la más fundamental presunción de que la totalidad antagónica no tiene un origen histórico preciso (como, en la reconstrucción de Postone, en el imperio del valor y el trabajo en el capitalismo), sino que se monta en una filosofía de la protohistoria de la modernidad de límites demasiado imprecisos. Reformular el pensamiento de Adorno de manera solvente exige, pues, reconducir la totalidad antagónica al plano de la especificidad histórica, mostrando que la dinámica auto-moviente del Weltgeist se funda en la dinámica fetichista del capital como valor que se auto-valoriza. Caso contrario, se corre el riesgo de caer en la "filosofía de la historia sin historia" de la que habla Schnädelbach o en la crítica "de la sociedad como tal" (y no de la sociedad capitalista) de la que habla O'Kane.

Ahora bien, allende su concepción de la emancipación frustrada, Adorno provee también una original teoría de la dominación social centrada en un concepto crítico de la totalidad. La totalidad social regida por el Weltgeist no encierra la clave de la emancipación humana sino la estructura fundamental del dominio sobre los particulares. De esto se desprende que una relectura del pensamiento de Adorno, en clave de la reformulación de Postone, puede conducirnos a rescatar los tramos más interesantes de su teoría crítica, librados ahora de la deriva pesimista y la filosofía negativa de la historia universal. Mediante un giro a la especificidad histórica en la categoría de totalidad antagónica, es posible enmarcar reflexivamente la dominación social en la lógica del capital, dando cuenta de su posible cancelación.

\section{Importancia de la concepción crítica de la totalidad}

Como sostuve en el apartado anterior, el pensamiento de Adorno indaga en torno a la imposibilidad de la totalidad social para construirse como un sistema completo y cerrado de dominación. Sin embargo, al mismo tiempo deshistoriza la noción de totalidad antagónica, al enmarcarla en una filosofía pesimista de la historia universal, donde no habría alternativas a la totalidad opresiva y su fracaso. La dialéctica negativa se detiene en el punto donde la incapacidad de la totalidad antagónica para plasmarse socialmente como un todo cerrado y coherente, redunda sobre su propio fracaso, sin que se abran posibilidades realizables de transformación. Esto conduce a una situación donde la totalidad antagónica no logra consolidar su sistema de dominación completamente carente de fisuras, pero a la vez se ve obturada su superación posible. El pensamiento de Adorno presenta dificultades de solvencia interna en la medida en que parece insistir en la simultaneidad del fracaso de la totalidad de la dominación y la imposibilidad en principio de la emancipación con respecto a la totalidad. Esta simultaneidad vuelve inconsistente el planteo 
crítico porque recusa su intencionalidad emancipatoria, de la que empero no puede prescindir, al tornarla aparentemente irrealizable.

Es posible superar el impasse mencionado, si se efectúa un giro más preciso a la especificidad histórica, situando el concepto de Weltgeist en una crítica categorial del capital independiente de cualquier filosofía negativa de la historia universal. Esta crítica categorial permite, también, formular con mayor precisión y claridad el sentido de una dialéctica de la sociedad moderna que apunte a las posibilidades liberadoras generadas por el capitalismo, que sin embargo lo trascienden. Resultaría viable repensar la teoría adorniana sobre la base de una crítica categorial de Postone, históricamente autorreflexiva y atenta a las posibilidad de un proyecto alternativo (y afirmativo) de modernidad que vaya más allá de la sociedad capitalista. De cara a esta reformulación posible, Adorno conserva centralidad por la claridad con que formuló un concepto crítico de la totalidad social. Al hacer de la totalidad antagónica un concepto central para la crítica social, Adorno se diferencia de otros pensadores hegel-marxistas que aspiran a realizar una totalidad al final de la historia.

La idea de emancipación sin totalidad configura la contracara liberadora de la dialéctica negativa adorniana, que sugiere la posibilidad de una reconciliación noidentificante entre universal y particular. Postone asume que el pesimismo adorniano está ligado directamente a la tesis de la no-identidad entre sujeto y objeto (Postone 2006: p. 173; fragmento ya citado). Esta lectura desconoce que en Adorno no hay una filosofía afirmativa de la totalidad, sino una teoría crítica de la totalidad como estructura de la dominación. La presunción de una continuidad de la no-identidad entre universal y particular es perfectamente compatible con la crítica de la totalidad social. Contra lo sostenido por Postone, el "pesimismo" de Adorno no es producto de su teoría de la no-identidad de sujeto y objeto sino, por el contrario, de la deshistorización de la dominación por la totalidad.

Se desprende del pensamiento de Adorno que lo universal y lo particular no pueden identificarse, pues el impulso a la identificación, principio de la sociedad mistificada, conduce a la totalidad de la contradicción. Cierta cuota de escisión, de no-coincidencia, es constitutiva de la sociabilidad. Adorno concibe la posibilidad de la reconciliación como asunción radical de lo no-idéntico en el seno de lo universal: "La reconciliación sería la rememoración de lo múltiple ya no hostil, que es anatema para la razón subjetiva" (Adorno 2008: p. 18). Su idea de reconciliación no está atada al ideal de la identidad, que es en cambio comprendido como fundamento de la dominación. La promesa de la reconciliación aspira a derribar la rígida identidad consigo de la totalidad social, habilitando el desaherrojamiento a lo particular y contingente.

La crítica social de Adorno se dirige a la autarquía de las formas de mediación social frente a los particulares. La universalidad social opresiva es aquélla que se 
haya autonomizada, que se funda en sí misma (en la identidad consigo de sus principios puros, en la recursividad del Weltgeist) y se desinteresa por las aspiraciones de los particulares que la sostienen. Lo que constituye al espíritu universal en una mediación social fetichista, es su identidad consigo mismo, su prescindencia con respecto a la gratificación de los particulares, que son sacrificados a la prosecución de los fines soberanos de lo universal.

La autonomización de lo universal social supone que éste se erige cada vez sobre sí mismo, sobre leyes propias indiferentes a los particulares, de modo que la pluralidad de lo social se ve subsumida a una totalidad superimpuesta. A la vez, la universalidad social reificada tiende a negar su carácter temporal e histórico. Las formas sociales reificadas aparecen como realidades naturales inamovibles: la ley de la sociedad capitalista "es natural por su carácter de inevitabilidad bajo las relaciones dominantes de producción" (Adorno 2008: p. 325). Lo universal social, una vez que se recluye en sí mismo, en sus fundamentos propios e indiferentes a lo particular, vela su carácter histórico. Sólo abrazando a lo particular, cediendo ante ello, podría lo universal revelarse como dinámico. Mientras remita a su dinámica automediadora tenderá a silenciar la contingencia histórica en la afirmación de su propia identidad consigo.

La recreación adorniana del ideario emancipatorio lleva a un original concepto de la felicidad como "redención de lo particular en cuanto principio universal" (Adorno 2008: p. 324). La idea de felicidad demanda un universal que recupere en su seno a lo particular. La universalidad prometida sería, de modo emancipado, lo que es hoy el espíritu del mundo como totalidad opresiva: un universal particular. El universal se particulariza de modo "malo", antagónico, en virtud de su cerrada identidad consigo. Al erigirse como universal sobre sus fundamentos autonomizados, excluye a lo particular, denunciándose a sí mismo como opresor particular. El proyecto de una forma de mediación social emancipada radica en la reversión de esta dialéctica opresiva, que haga posible una universalidad orientada a lo particular, no dotada de un fundamento exterior y autárquico. Ello supondría dinamizar los fines autonomizados de la vida social (como la acumulación de capital, que se preocupa por la reproducción ampliada del valor antes que por los intereses de los individuos). La organización de la sociedad, entonces, no respondería a otro propósito que la felicidad de los particulares. Esta promesa emancipatoria exige que no haya ningún fin social válido en sí mismo por encima o a espaldas de la gratificación de los particulares reunidos. Esto habilitaría una nueva organización social, tal que "semejante organización tendría su telos en la negación del sufrimiento físico en el último de sus miembros" (Adorno 2008: p. 192).

Este proyecto emancipador apuesta también al acogimiento de la caducidad en la dinámica de la vida colectiva. "La felicidad no es una invariante, sólo lo es la infelicidad, que tiene su esencia en la perennidad" (Adorno 2008: p. 324). Antes señalé 
que el espíritu universal, al cosificarse, se impermeabiliza al cambio y se erige como pseudo-natural. Tiende a velar su carácter histórico y transitorio, dándose la apariencia de algo fundado en sí mismo y por lo tanto eterno. La promesa de emancipación que sugiere Adorno no aspira a fundar un orden inmóvil y cerrado, sino a radicalizar las capacidades de auto-interrogación y auto-alteración de las instituciones sociales, abriendo lo universal social a su propia contingencia y alterabilidad.

\section{Conclusión}

En este trabajo intenté evaluar la legitimidad y el alcance de la acusación, usualmente dirigida a Adorno, de caer en un pesimismo sin salida. En las primeras secciones del trabajo intenté mostrar que esta acusación tiene por lo menos un sustento textual parcial en la medida en que Adorno parece situar la dominación social en una filosofía de la historia de bases demasiado generales, lo que tiende a desdibujar la perspectiva de una emancipación realizable. En las última sección intenté mostrar que, más allá de la deriva pesimista, Adorno sienta las bases para una vigorosa formulación del ideario emancipatorio de la teoría crítica, que ya no esté atada a la postulación afirmativa de la totalidad. La idea adorniana de la felicidad como restitución de lo particular en medio de lo universal permite imaginar un concepto de emancipación sin identidad. Intenté, por lo tanto, mostrar la importancia de revisitar el pensamiento de Adorno, habida cuenta de sus dificultades, de cara a la continuación actual de la teoría crítica de la sociedad con intencionalidad emancipatoria.

\section{Referencias bibliográficas}

Adorno, T. W. (2008): Dialéctica Negativa, Madrid, Akal.

Adorno, T. W. y Horkheimer, M. (2002): Dialéctica del iluminismo, Buenos Aires, Editora Nacional.

Anderson, P. (1979): Considerations on Western Marxism, Londres, New Left Books.

Arthur, C. (2004): The New Dialectic and Marx's Capital, Londres, Brill.

BACKhaus, H. G. (1997) Dialektik der Wertform. Untersuchungen zur Marxhschen Ökonomiekritik, Freiburg, Ca Ira.

Braunstein, D. (2011) Adornos Kritik der Politischen Ökonomie, Bielefeld, Suhrkamp.

CАBOT, M. (1993) "De Habermas a Adorno: sentido de un «retroceso»" en Estudios

Filosóficos, num. 121 (1993), pp. 451-478, ISSN 0210-6086.

Cook, D. (2002): Adorno on Nature, Camdridge, Acumen. 
Cook, D. (2006): “Adorno's critical materialism”, en Philosophy social criticism, vol. 32, Boston.

Habermas, J. (1987): Teoría de la acción comunicativa, Madrid, Taurus.

Habermas, J. (1989): El discurso filosófico de la modernidad, Madrid, Taurus.

Horkheimer, M. (1974): Teoría Crítica, Buenos Aires, Amorrortu.

Jameson, F. (2010): Marxismo Tardio. Adorno y la persistencia de la dialéctica, Méjico, FCE.

JAY, M. (1974): La imaginación dialéctica. Una historia de la Escuela de Frankfurt y el Instituto de Investigación Social (1923-1950), Madrid, Taurus.

JAY, M. (1984): Marxism and Totality, Los Angeles, UCLA Press.

LuKÁCS, G. (1985): Historia y conciencia de clase, Madrid, Grijalbo.

MAiso Blasco, J. (2010): Elementos para la reapropiación de la teoría crítica de Theodor W. Adorno, Salamanca, Ediciones Universidad de Salamanca.

MARX, K. (1971): Elementos fundamentales para la crítica de la economía política (Grundrisse) 1857-1858, Tomo 1, Méjico, Siglo XXI.

MarX, K. (1975): El capital, Tomo I, Vol I, Buenos Aires, Siglo XXI.

O’Kane, C. (2013) Fetishism and Social Domination in Marx, Lukács, Adorno and Lefebvre, https://reificationofpersonsandpersonificationofthings.files.wordpress.com/2013/06/chris-okane-thesis-final.pdf (último acceso 09/07/2015)

PENSKy, M. (2004): "Natural History: the life and afterlife of a concept in Adorno" en Critical Horizons, Vol. 5, N 1, Lancaster, John Rundell Editor.

Postone, M. (2006): Tiempo, trabajo y dominación social, Madrid, Marcial Pons. Postone, M. (2009): History and heteronomy. Critical Essays, Tokio, UTCP.

RenAult, E. (2010): “A critical theory of social suffering” en Critical Horizons, Vol. 11, $\mathrm{N}^{\mathrm{o}}$ 2, Lancaster, John Rundell Editor.

SCHNÄDElBACH, H. (2004): Analytische und Postanalytische Philosophie, Frankfurt a/M., Suhrkamp.

SchwArzBöck, S. (2008): Adorno y lo politico, Buenos Aires, Prometeo.

SCHWEPPENHÄUSER, G. (1993) Ethik nach Auschwitz. Adornos negative Moralphilosophie, Argument: Hamburg.

Sherrat, Y (2002): Adorno's Positive Dialectic, Cambridge, Cambridge University Press.

Sotelo, L. (2009): Ideas de la historia. La escuela de Frankfurt: Adorno, Horkheimer y Marcuse, Buenos Aires, Prometeo.

Wellmer, A. (1993): La dialéctica de modernidad y posmodernidad. La crítica de la razón después de Adorno, Madrid, La Balsa de la Medusa.

Weyand, J (2001) Adornos Kritische Theorie des Subjekts, Lüneburg, Zu Klampen. ZAMORA, J. (1999) "La teología «inversa» de Adorno: Salvar la religión en su completa profanización” en: Proyecto Filosofía después del Holocausto - Instituto de Filosofía (CSIC), http://www.foroellacuria.org/JAZam/JAZam-Texto13.htm 
ZAMORA, J. (2004) "Adorno, un pensador de nuestro tiempo" en: Vida Nueva, (Pliego) n. ${ }^{\circ}$ 2.426, 29 de mayo 2004, 23-30, http://www.foroellacuria.org/ JAZam/JAZam-Texto30.htm.

Facundo Nahuel Martín

Universidad de Buenos Aires

Centro de Investigaciones Filosóficas (CONICET)

facunahuel@gmail.com 